\title{
Definitive external-beam radiotherapy versus radical prostatectomy in clinically localized high-risk prostate cancer: a retrospective study
}

Fundagul Andic ${ }^{1,6^{*}}$ D, Volkan Izol $\left.\right|^{2}$, Serkan Gokcay ${ }^{3}$, Hasan Suat Arslantas', Yildirim Bayazit ${ }^{2}$, Hatice Coskun ${ }^{4}$, Mustafa Zuhtu Tansug ${ }^{2}$ and Yasar Sertdemir ${ }^{5}$

\begin{abstract}
Background: Optimal treatment of high-risk prostate cancer remains controversial. We aimed to compare treatment outcomes of prostate cancer patients treated with definitive external-beam radiotherapy (ExRT) or radical prostatectomy (RP).

Methods: The records of 120 high-risk clinical stage T2b-T4 NO M0 prostate cancer patients treated with definitive ExRT or RP were reviewed. Patients with pretreatment prostate-specific antigen (PSA) levels $\geq 20 \mathrm{ng} / \mathrm{mL}$ or clinical $\geq T 3$ stage or Gleason score (GS) $\geq 8$ were included in the study. Biochemical failure free survival (BFFS), distant metastasis free survival (DMFS), cancer-specific survival (CSS) and overall survival (OS) were analyzed. Cox regression analysis was performed to determine predictors of BF.

Results: Seventy-two patients received definitive ExRT with androgen-deprivation therapy in $95.8 \%$ and 48 patients underwent RP with pelvic lymph node dissection. Mean age $(67.7 \pm 6.6$ vs $64.5 \pm 7.6$ year, $p=0.017)$ and the rate of patients with PSA levels $\geq 20 \mathrm{ng} / \mathrm{mL}(69.4 \%$ vs $47.9 \%, p=0.022)$ were higher in the definitive ExRT group than the RP group. Distributions of GS and clinical T stage were similar. Mean follow-up was 60.2 \pm 30.3 months in the definitive ExRT group and $41.3 \pm 21.5$ months in the RP group $(p<0.001)$. Twenty-five $\%$ of the RP group received adjuvant ExRT and $41.7 \%$ received salvage ExRT. Biochemical failure was significantly higher $(52.1 \%$ vs $21.4 \%, p<0.001)$ and the mean BFFS was significantly lesser (34.4 \pm 3.9 vs $97.8 \pm 5.9$ months, $p<0.001)$ in the RP group than the definitive ExRT group. However, DMFS, CSS and OS were similar in both groups. In multivariate analysis, being in the RP group significantly increased the risk of BF $(p<0.001)$. Furthermore, not receiving pelvic lymphatic irradiation in the definitive ExRT group $(p=0.048)$ and having positive surgical margin in the RP group $(p=0.050)$ increased the risk of BF.

Conclusions: BF was significantly higher and the mean BFFS was significantly lesser in high-risk prostate cancer patients undergoing RP than definitive ExRT while DMFS, CSS and OS were similar in both treatment groups.
\end{abstract}

Keywords: High-risk prostate cancer, Radiotherapy, Radical prostatectomy, Treatment outcomes

\footnotetext{
* Correspondence: fgandic@gmail.com

${ }^{1}$ Faculty of Medicine, Department of Radiation Oncology, Cukurova

University, Adana, Turkey

${ }^{6}$ Balcali Hastanesi, Radyasyon Onkolojisi AD, Cukurova Universitesi, 01330

Sarıcam, Adana, Turkey

Full list of author information is available at the end of the article
}

(c) The Author(s). 2019 Open Access This article is distributed under the terms of the Creative Commons Attribution 4.0 International License (http://creativecommons.org/licenses/by/4.0/), which permits unrestricted use, distribution, and reproduction in any medium, provided you give appropriate credit to the original author(s) and the source, provide a link to the Creative Commons license, and indicate if changes were made. The Creative Commons Public Domain Dedication waiver (http://creativecommons.org/publicdomain/zero/1.0/) applies to the data made available in this article, unless otherwise stated. 


\section{Background}

High-risk disease accounts approximately $30 \%$ of prostate cancer $(\mathrm{PCa})[1,2]$. However, the current definitions of high-risk $\mathrm{PCa}$ include a heterogeneous group of patients with a range of prognoses and the optimal management of the subgroups is under debate [3-7].

Local treatment of high-risk PCa provides local control and also prevents further seeding of distant metastatic sites. Conventionally, high-risk PCa patients are treated with a combination of definitive external-beam radiotherapy (ExRT) and androgen-deprivation therapy (ADT) [8-10]. However, recent published data suggests that radical prostatectomy (RP) shows excellent local tumor control and similar oncological results in high-risk $\mathrm{PCa}$ patients, especially in combination with multimodal treatments involving ADT and radiotherapy [11-14]. Consequently, the American Urological Association (AUA) and European Association of Urology (EAU) support RP with extended pelvic lymph node dissection (PLND) as an optional treatment for a selective group of patients in the context of multimodal treatment $[3,4]$.

While outcomes for definitive ExRT and RP have been published independently these treatments have not been compared prospectively and the optimal management of high-risk PCa is still controversial. However, side effect profiles of definitive ExRT and RP might play a role in the decision of treatment. Treatment specific quality of life studies in clinically localized PCa demonstrate that sexual function and urinary control are better after ExRT than RP and gastro-intestinal side effects are more common after ExRT [15, 16]. Furthermore, adverse events due to combination of radiotherapy with long-term ADT, such as heart failure, arrhythmia, liver dysfunction, glucose intolerance, hot flush and diabetes may pose additional problems $[17,18]$.

In this single-institution retrospective study, we aimed to analyze the treatment outcomes of high-risk PCa patients either treated with definitive ExRT or RP as first-line treatment of the disease.

\section{Methods}

This study is approved by the Institutional Ethics Review Board.

The records of 120 patients with clinical stage T2b-T4 NO M0 high-risk PCa who were treated with definitive ExRT or RP with PLND and/or followed at the Departments of Radiation Oncology and Urology between August 2007 and March 2018 were analyzed retrospectively. Patients were staged according to the seventh edition of the American Joint Committee on Cancer Classification and Staging of Tumors [19].

Eligibility criteria included: untreated, high-risk, clinical node negative, none-metastatic, histologically confirmed adenocarcinoma of the prostate. Patients at least having one of the following factors at pretreatment diagnostic evaluation: prostate-specific antigen (PSA) level $\geq 20 \mathrm{ng} / \mathrm{mL}$, clinical $\geq \mathrm{T} 3$ stage and Gleason score (GS) $\geq 8$ were accepted as high-risk PCa as defined in the AUA guideline [3].

All patients were evaluated with complete history, physical examination and blood PSA counts. Pelvic computed tomography (CT) and or magnetic resonance imaging, and bone scan were used for staging. Additionally, positron emission tomography (PET)/CT scan or prostate-specific membrane antigen PET /CT were applied in some patients as a part of their workup.

Follow-up of asymptomatic patients included disease specific history and blood PSA measurement at least 3 times (at three, six and twelve months) in the first year after treatment, then every six months until three years, and then annually. Restaging work-up was done if necessary. Examination intervals were adjusted individually at biochemical and clinical progression. Patient follow-up was completed through the review of medical records and phone calls from the patients.

In patients who underwent RP, a detectable or rising PSA value after surgery that is $\geq 0.2 \mathrm{ng} / \mathrm{ml}$ with a second confirmatory level is accepted as biochemical failure (BF) and the date of BF is accepted as the first rise $(\geq 0.2$ $\mathrm{ng} / \mathrm{mL}$ ) in PSA [20]. In patients receiving definitive ExRT, a PSA rise of $\geq 2 \mathrm{ng} / \mathrm{mL}$ above the nadir PSA after radiotherapy is accepted as $\mathrm{BF}$ and the date of $\mathrm{BF}$ is defined by the time the rise in PSA $(\geq 2 \mathrm{ng} / \mathrm{mL}$ above the nadir) [21].

Postoperative ExRT was accepted as adjuvant if ExRT was started before BF without local and distant metastatic disease within 6 months after RP and accepted as salvage if ExRT was started after local and/or BF without distant metastatic disease. The decision of adjuvant or salvage ExRT and/or ADT were made by an urologist in cooperation with a radiation oncologist. The patients with positive surgical margins and positive lymph nodes were mostly treated with adjuvant ExRT. However, the patients with negative surgical margins and negative lymph nodes were most regularly followed-up and were further treated if they concluded with clinical failure.

Following definitive treatment, patients who have only BF with or without local recurrence are assessed for salvage local therapy often combined with ADT and patients who have subsequent metastatic disease received docetaxel or abiraterone acetate in combination with ADT.

Upgrading and downgrading of GS were defined as an increase or decrease, respectively, from one prognostic risk group to another, similar to upstaging and downstaging of $\mathrm{T}$ stage. Based on the AUA guideline, prognostic risk groups for GS were defined as follows: GS $\leq 6$ (low 
risk), GS 7 (intermediate risk), and GS $\geq 8$ (high risk) and prognostic risk groups for $\mathrm{T}$ stage were defined as follows: $\leq \mathrm{T} 2 \mathrm{a}$ (low risk), T2b-T2c (intermediate risk) and $\geq$ T3 stage (high risk) [3].

\section{End points}

Mean follow-up was $60.2 \pm 30.3$ months in the definitive ExRT group and $41.3 \pm 21.5$ in the RP group. The primary end point was the rate of $\mathrm{BF}$ and $\mathrm{BF}$ free survival (BFFS). Additionally, distant metastases free survival (DMFS), cancer-specific survival (CSS) and overall survival (OS) were analyzed.

Possible predictive risk factors for $\mathrm{BF}$ were defined as age, pretreatment PSA level $\geq 20 \mathrm{ng} / \mathrm{mL}, \mathrm{GS} \geq 8$ at biopsy and RP specimen, clinical and pathological $\geq \mathrm{T} 3$ tumor, pathological N1 stage, positive surgical margins, pelvic lymphatic irradiation (PLI) and short term ( $<2$ year) ADT use.

In the definitive ExRT group, in order to analyze whether duration of ADT may predict BF or not, ADT duration was calculated from the day of initiation of ADT to the last day of ADT effectiveness in cases without $\mathrm{BF}$ and to the day of $\mathrm{BF}$ in cases with $\mathrm{BF}$.

\section{Statistical analysis}

All analyses were performed using IBM SPSS Statistics for Windows Version 19.0 statistical software package (Armonk, NY: IBM Corp). Categorical variables were expressed as numbers and percentages, whereas continuous variables were summarized as mean and standard deviation and as median and minimum-maximum where appropriate. Chi-square/Fisher Exact test was used to compare categorical variables between groups. For comparison of continuous variables between two groups, the Student's t-test or Mann-Whitney U test was used depending on whether the statistical hypotheses were fulfilled or not. Kaplan-Meier method and log rank test was performed for survival analysis. Cox regression analysis was performed to determine significant predictors of BF. Results of univariate and multivariate Cox regression analysis are given with odds ratio and 95\% confidence interval. The statistical level of significance for all tests was considered to be 0.05 .

\section{Results}

Seventy-two (60\%) patients underwent definitive ExRT and 48 (40\%) patients underwent RP with PLND as first-line therapy of high-risk PCa. The characteristics of high-risk PCa patients are shown in Table 1. No difference with regard to pretreatment clinical T stage and GS was found between the treatment groups. However, pretreatment mean PSA levels $(p=0.049)$ and the rate of patients with pretreatment PSA levels $\geq 20 \mathrm{ng} / \mathrm{mL}$ ( $p=$ 0.022 ) were significantly higher in the definitive ExRT group than the RP group.

Sixty-nine (95.8\%) of the patients receiving definitive ExRT also received ADT in combination with ExRT as first-line treatment. ADT was not prescribed in three patients because of their cardiovascular comorbidities. While $65.3 \%(n=47)$ of the patients receiving definitive ExRT received ADT $\geq 2$-years, $25 \%(n=18)$ of them received $\geq 1$-year to $<2$-year and $5.6 \%(n=4)$ of them received less than $<1$-year.

All patients had RP with extended PLND. However, 3 patients underwent surgery at an outside facility. Pathological characteristics of RP are given in Table 2 . Forty-four out of 48 (91.7\%) patients who underwent RP had adverse pathological risk factors $(\geq \mathrm{T} 3$ tumor and/or positive surgical margins and/or positive lymph nodes and or $\mathrm{GS} \geq 8$ ).

Characteristics of definitive, adjuvant and salvage ExRT are given in Table 3. Three-dimensional conformal

Table 1 Characteristics of patients

\begin{tabular}{|c|c|c|c|}
\hline & $\operatorname{ExRT}(n=72)$ & $\mathrm{RP}(n=48)$ & $p$ \\
\hline Age (years) & $67.7 \pm 6.667 .2(43.9-80.1)$ & $64.5 \pm 7.665 .3(47.3-79.9)$ & 0.017 \\
\hline Follow-up (months) & $60.2 \pm 30.353 .7(10.3-125.8)$ & $41.3 \pm 21.537 .8(9.6-128.9)$ & $<0.001$ \\
\hline Pretreatment PSA (ng/mL) & $34.6 \pm 30.725 .4(3.4-172)$ & $27.2 \pm 26.317(3.2-138.7)$ & 0.049 \\
\hline Pretreatment PSA $\geq 20$ ng/mL n (\%) & $50(69.4)$ & $23(47.9)$ & 0.022 \\
\hline \multicolumn{4}{|l|}{ Clinical T stage n (\%) } \\
\hline $\mathrm{T} 2$ & $46(63.9)$ & $35(72.9)$ & \multirow[t]{3}{*}{0.474} \\
\hline T3 & $22(30.6)$ & $12(25.0)$ & \\
\hline T4 & $4(5.6)$ & $1(2.1)$ & \\
\hline \multicolumn{4}{|l|}{ Gleason score (biopsy) n (\%) } \\
\hline 6 & $17(23.6)$ & $8(16.7)$ & \multirow[t]{3}{*}{0.636} \\
\hline 7 & $15(20.8)$ & $10(20.8)$ & \\
\hline$>8$ & $40(55.6)$ & $30(62.5)$ & \\
\hline
\end{tabular}

ExRT, external-beam radiotherapy; $R P$, radical prostatectomy; $P S A$, prostate-specific antigen 
Table 2 Pathological characteristics of radical prostatectomy

\begin{tabular}{|c|c|}
\hline Extended PLND n (\%) & $48(100)$ \\
\hline Removed LN & $13.3 \pm 7.412(5-38)$ \\
\hline N1 stage n (\%) & $16(33.3)$ \\
\hline Positive surgical margin n (\%) & $28(58.3)$ \\
\hline \multicolumn{2}{|l|}{ Gleason score n (\%) } \\
\hline 6 & $2(4.2)$ \\
\hline 7 & 19 (39.6) \\
\hline$\geq 8$ & $27(56.3)$ \\
\hline Gleason score upgrading n (\%) & $8(16.7)$ \\
\hline Gleason score downgrading n (\%) & $7(14.6)$ \\
\hline \multicolumn{2}{|l|}{ T stage n (\%) } \\
\hline $\mathrm{T} 2$ & $9(18.8)$ \\
\hline T3 & $38(79.2)$ \\
\hline T4 & $1(2.1)$ \\
\hline T stage upgrading n (\%) & $25(52.1)$ \\
\hline T stage downgrading n (\%) & $0(0)$ \\
\hline
\end{tabular}

PLND: pelvic lymph node dissection; $L N$ : lymph nodes

radiation therapy (3D-CRT) or intensity modulated radiation therapy (IMRT) techniques were used in all 104 patients receiving ExRT. However, 11.5\% of the patients (5 in definitive ExRT group, 4 in adjuvant ExRT group and 3 in salvage ExRT group) received their ExRT at an outside facility.

In the RP group, 12 (25\%) patients received adjuvant ExRT and 20 (41.7\%) patients received salvage ExRT for local and/or BF. Furthermore, 9 of the patient in adjuvant ExRT group and 12 of the patients in salvage ExRT group also received ADT in combination with ExRT.

Prior to salvage ExRT, median PSA level of totally 20 patients was 1.09 (0.25-43.5). Salvage ExRT was administered at a PSA level of $<0.5 \mathrm{ng} / \mathrm{mL}$ in $3(15 \%)$ patients, at a PSA level of 0.5 to 1.5 in $10(50 \%)$ patients and $>1.5$ $\mathrm{ng} / \mathrm{mL}$ in 7 (35\%) patients.

Table 3 Characteristics of external-beam radiotherapy

\begin{tabular}{|c|c|c|c|}
\hline & $\begin{array}{l}\text { Definitive ExRT } \\
(n=72)\end{array}$ & $\begin{array}{l}\text { Adjuvant ExRT } \\
(n=12)\end{array}$ & $\begin{array}{l}\text { Salvage ExRT } \\
(n=20)\end{array}$ \\
\hline Volume & $P+S V+/-P L I$ & $\begin{array}{l}\text { Operation bed } \\
+/-\mathrm{PLI}\end{array}$ & $\begin{array}{l}\text { Operation bed } \\
+/-\mathrm{PLI}\end{array}$ \\
\hline Dose* & 74 Gy (70-76) & 66 Gy (60-70.2) & 66 Gy (60-74) \\
\hline PLI n (\%) & $18(25.0)$ & $3(33.3)$ & $8(40)$ \\
\hline \multicolumn{4}{|c|}{ Technique n (\%) } \\
\hline 3D-CRT & $65(90.3)$ & $10(83.3)$ & $18(90)$ \\
\hline IMRT & $7(9.7)$ & $2(16.7)$ & $2(10)$ \\
\hline
\end{tabular}

ExRT, external-beam radiotherapy; $P$, prostate; $S V$, seminal vesicle; $P L I$, pelvic lymphatic irradiation; 3D-CRT, three-dimensional conformal radiotherapy; IMRT, intensity modulated radiotherapy

*, radiotherapy was given with $1.8-2$ Gy daily fraction dose
Risk groups of GS were confirmed on RP specimen in $33(68.8 \%)$ out of 48 patients who underwent RP. Eight patients (16.7\%) had upgrading on RP specimen: 4 patients upgraded from a low risk GS 6 to an intermediate risk GS 7, 2 patients from a low risk GS 6 to a high risk GS 9 and 2 patients from an intermediate risk GS 7 to a high risk GS 8. Furthermore, 7 (14.6\%) patients had downgrading on RP specimen from a high risk GS 8 to an intermediate risk GS 7.

Risk groups of clinical $\mathrm{T}$ stages were confirmed on RP specimen in $23(47.9 \%)$ out of 48 patients. However, 25 (52.1\%) patients had upstaging on RP specimen from a T2b-T2c stage to a T3 stage in 24 patients and from a T2c to a T4 stage in 1 patient.

Treatment outcomes according to the treatment groups are given in Figs. 1, 2, 3 and 4 and Table 4. BF was significantly higher $(52.1 \%$ vs $21.4 \%, p<0.001)$ and the mean BFFS was significantly lesser $(34.4 \pm 3.9$ vs $97.8 \pm 5.9$ months, $\mathrm{p}<0.001$ ) in the RP group than the definitive ExRT group. However, distant metastasis, cancer-specific mortality, all-cause mortality, DMFS, CSS and OS were similar in both groups.

Results of the univariate Cox regression analyses for potential predictors of $\mathrm{BF}$ are given in Table 5. When all patients were included, univariate analysis showed that being in the treatment group RP was the only significant $(\mathrm{p}<0.001)$ predictor of $\mathrm{BF}$ while age was borderline significant $(p=0.066)$ and multivariate analysis showed that being in the treatment group RP was still the only significant $(p<0.001)$ predictor of $\mathrm{BF}$ and pretreatment PSA level $\geq 20 \mathrm{ng} / \mathrm{mL}$ was borderline significant $(p=0.069)$. When only definitive

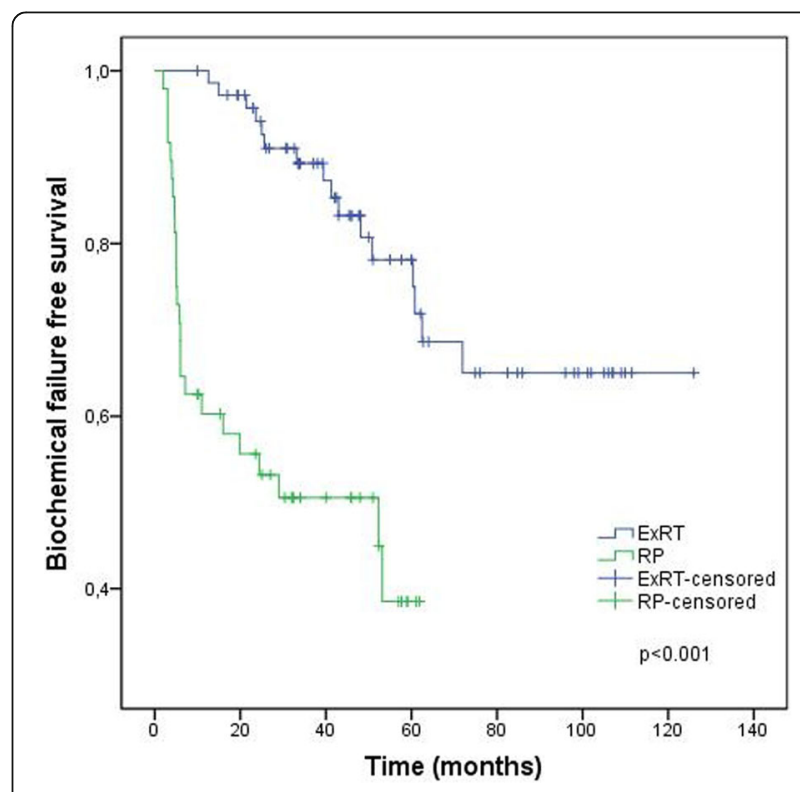

Fig. 1 Biochemical failure free survival. ExRT, external-beam radiotherapy; $\mathrm{RP}$, radical prostatectomy 


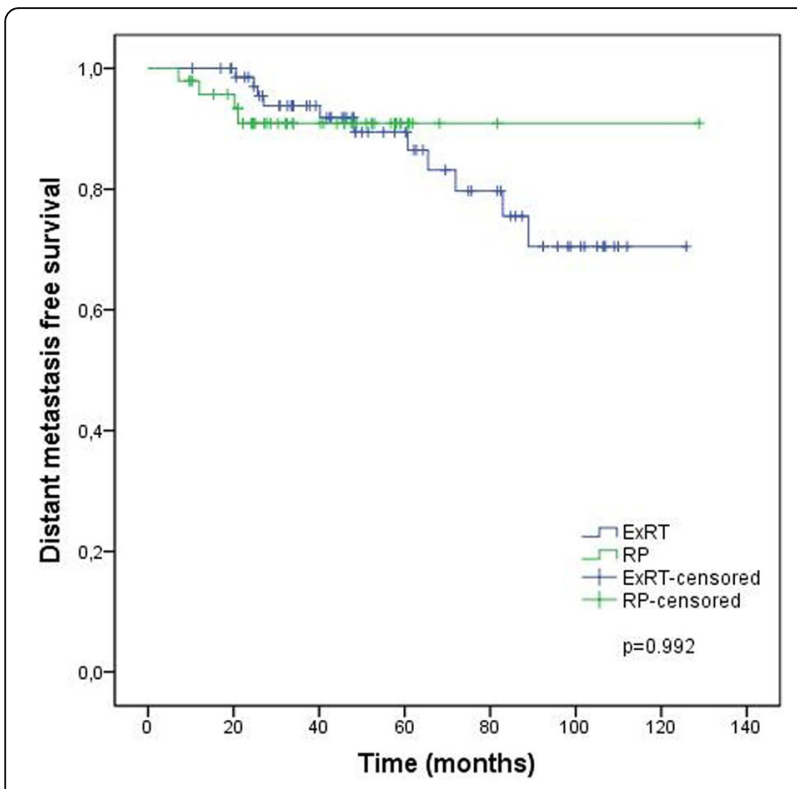

Fig. 2 Distant metastasis free survival. ExRT, external-beam radiotherapy; $\mathrm{RP}$, radical prostatectomy

ExRT treatment group was included, univariate analysis showed that not receiving PLI was borderline significant $(p=0.071)$ to predict $\mathrm{BF}$ and multivariate analysis showed that after risk adjustment according to $\geq 2$-year ADT use, BF risk was significantly higher in patients who did not receive PLI $(p=0.048)$ than patients who received. When only RP treatment group was included, both univariate and multivariate analysis showed that positive surgical margin was the only significant $(p=0.050)$ predictor of BF.

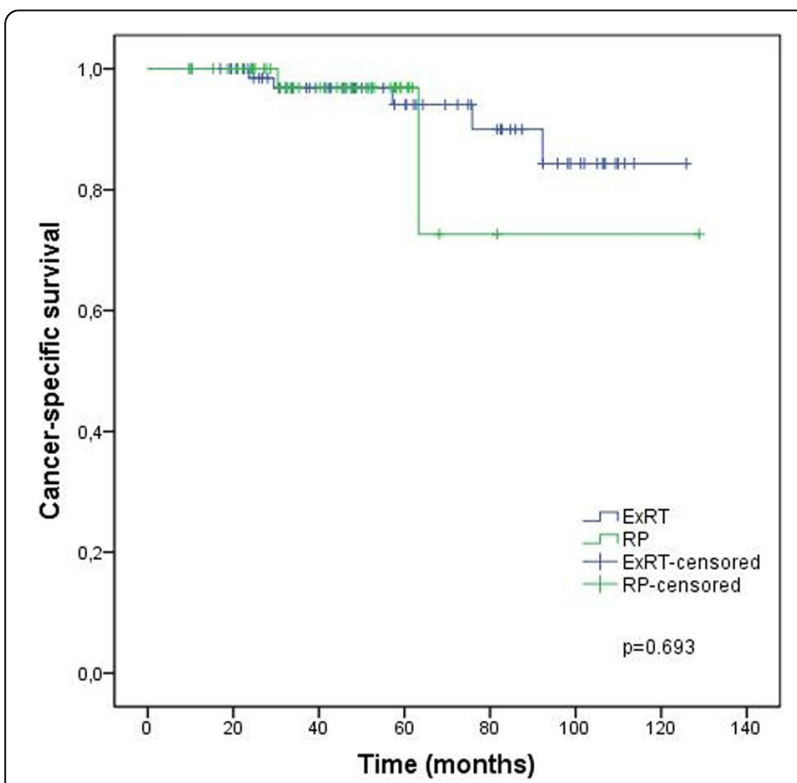

Fig. 3 Cancer-specific survival. ExRT, external-beam radiotherapy; RP, radical prostatectomy

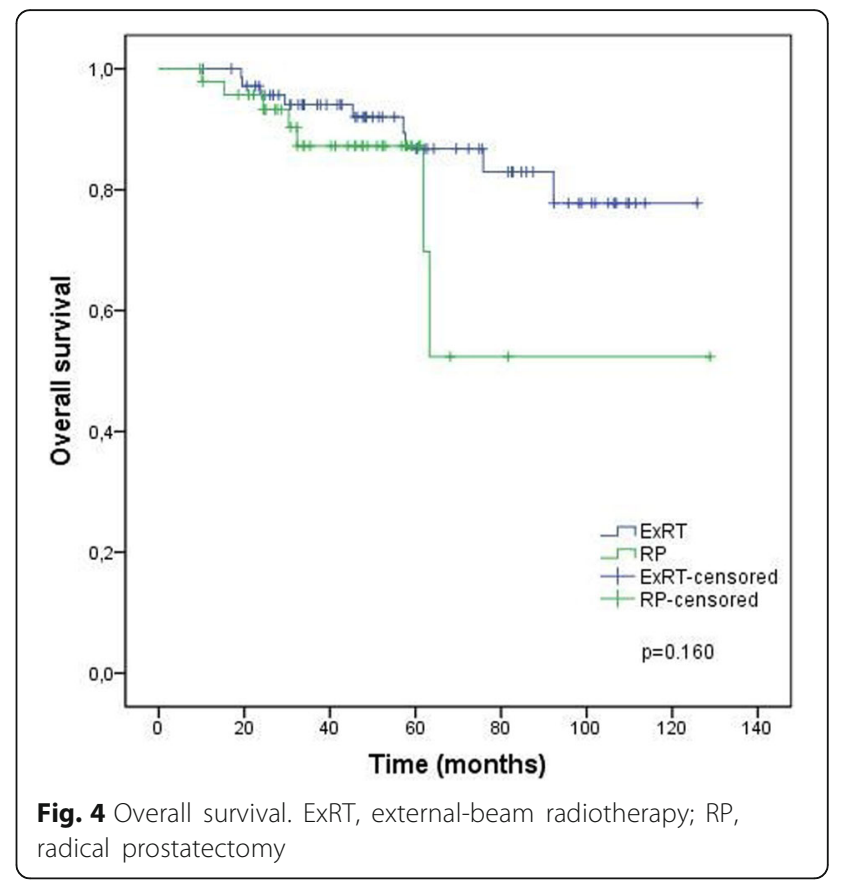

\section{Discussion}

There is no consensus on the best treatment for high-risk $\mathrm{PCa}$ patients. Options include definitive ExRT with ADT or RP with PLND followed by adjuvant radiotherapy in cases with unfavorable pathological features. The results of this study showed that the rate of BF was significantly higher $(52.1 \%$ vs $21.4 \%, p<0.001)$ and the mean BFFS was significantly lesser $(34.4 \pm 3.9$ vs $97.8 \pm 5.9$ months, $p<0.001)$ in the RP group than the definitive ExRT group. Five-year BFFS was 38.5 and $78.1 \%$ in the RP and the definitive ExRT group, respectively. Furthermore, 5-year DMFS, CSS and OS were similar in both groups. In multivariate analysis, when all patients were included, being in the treatment group RP significantly increased the risk of BF $(\mathrm{p}<0.001)$ and pretreatment PSA levels $\geq 20 \mathrm{ng} / \mathrm{mL}$ was borderline significant $(p=0.069)$; when only definitive ExRT group was included, after risk adjustment according to $\geq 2$-year ADT use, not receiving PLI significantly increased the risk of BF ( $p=0.048)$; and when only RP group was included, positive surgical margin was the only significant $(p=0.050)$ predictor of BF.

Suggestion of RP as a first-line treatment option in high-risk PCa patients is based on several large published retrospective series demonstrating favorable 10 -year CSS rates ranging around 90 to $80 \%$ and 5-year BFFS rates ranging around 70 to $50 \%[12,22-24]$. However, such high survival rates and high BFFS rates may be associated with the definitions of high-risk disease and thus capturing the patients with more favorable high-risk disease. In our study, 5-year CSS rate was $96.9 \%$ and 5 -year BFFS was $38.5 \%$ in the RP group. 
Table 4 Outcomes of treatment groups

\begin{tabular}{|c|c|c|c|}
\hline Treatment Outcomes & Definitive ExRT $(n=72)$ & $\mathrm{RP}(n=48)$ & $\mathrm{p}$ \\
\hline $\mathrm{BF} n(\%)$ & $16(21.4)$ & $25(52.1)$ & $<0.001$ \\
\hline Mean BFFS (months) & $97.8 \pm 5.9$ & $34.4 \pm 3.9$ & $<0.001$ \\
\hline 3 year BFFS (\%) $(95 \% \mathrm{Cl})$ & 89.3 (95 81.7-96.9) & $50.6(36.1-65.1)$ & \\
\hline 5 year BFFS (\%) $(95 \% \mathrm{Cl})$ & $78.1(66.7-89.5)$ & $38.5(20.1-56.9)$ & \\
\hline $\mathrm{DM} n(\%)$ & $11(15.3)$ & $4(8.3)$ & 0.399 \\
\hline Mean DMFS (months) & $106.6 \pm 5.1$ & $118.5 \pm 4.9$ & 0.992 \\
\hline 3-year DMFS (\%) (95\% Cl) & $93.8(87.9-99.7)$ & $90.9(82.4-99.4)$ & \\
\hline 5-year DMFS (\%) (95\% Cl) & $89.5(81.4-97.6)$ & $90.9(82.4-99.4)$ & \\
\hline Cancer-specific mortality n (\%) & $5(6.9)$ & $2(4.2)$ & 0.701 \\
\hline Mean CSS (months) & $116.9 \pm 5.1$ & $109.9 \pm 14.0$ & 0.693 \\
\hline 3 year CSS (\%) & $96.8(92.5-100.0)$ & $96.9(90.8-100.0)$ & \\
\hline 5 year CSS (\%) & $94.1(87.2-100.0)$ & $96.9(90.8-100.0)$ & \\
\hline All-cause mortality n (\%) & $9(12.5)$ & $7(14.6)$ & 0.788 \\
\hline Mean OS (months) & $110.9 \pm 4.6$ & $92.3 \pm 13.4$ & 0.160 \\
\hline 3 year OS (\%) $(95 \% \mathrm{Cl})$ & $94.1(88.4-99.7)$ & $87.2(76.6-97.9)$ & \\
\hline 5 year OS (\%) $(95 \% \mathrm{Cl})$ & $86.8(77.2-96.3)$ & $87.2(76.6-97.9)$ & \\
\hline
\end{tabular}

ExRT, external-beam radiotherapy; $R P$, radical prostatectomy; $B F$, biochemical failure; $B F F S$, biochemical failure free survival; $D M$, distant metastasis; $D M F S$, distant metastasis free survival; CSS, cancer-specific survival; OS, overall survival

Furthermore, several studies have retrospectively compared RP with ExRT in high-risk PCa patients. In a combined analysis including 1238 patients undergoing RP and 609 patients undergoing ExRT with or without ADT, 10-year CCS rates were 92, 92, and $88 \%$ for patients receiving RP, ExRT with ADT, and ExRT alone, respectively $(p=0.06)$ [25]. After multivariable risk adjustment, there was no significant difference in DMFS or CSS. However, the risk of all-cause mortality was greater after ExRT with ADT when compared to RP which could be explained by selection bias and contribution of potential adverse cardiovascular effects of ADT [25]. In our study 5-year DMFS and 5-year CCS was similar (89.5\% vs 90.9 and $94.1 \%$ vs $96.9 \%$ ) in the definitive ExRT and the RP groups, respectively, as well as the rate of all-cause mortality $(86.8 \%$ vs 87.2\%).

In a retrospective study from Italy reported outcomes of 288 patients with high-risk PCa either underwent ExRT $(n=162)$ in combination with nine months of ADT or underwent $(n=122)$ RP with pelvic lymph node sampling. Three-year BFFS favored ExRT targeted to prostate and seminal vesicle without PLI $(86.8 \%$ vs $69.8 \%, p=0.001$ ) [26]. However, ADT duration was none-optimal and follow-up period was relatively short. In our study, $95.8 \%(n=69)$ of the patients receiving definitive ExRT also received ADT in combination with ExRT as initial treatment. Furthermore, ADT duration was $\geq 2$-years in $65.3 \%(n=47)$ of the patients and $\geq$ 1 -year to $<2$-year in $25 \%(n=18)$ of them.
Another retrospective study reported $7.8 \%$ absolute benefit in 8-year metastatic progression with RP compared to ExRT in a high-risk cohort of PCa patients [27]. However, omission of PLI and short term (3 to 6 months) ADT use in combination with ExRT and higher pretreatment risk factors (PSA, clinical stage, and GS) in the ExRT group than the RP group were the major limitations of the study [27]. In our study, 5-year DMFS were similar in both treatment groups. Furthermore, use of $\geq 2$-years ADT in $65.3 \%$ and performing PLI in $25 \%$ of the definitive ExRT group, and similar distribution of pretreatment clinical stage and GS in both groups likely offered a healthier assessment in our study.

Based on three prospective randomized trials showing clinical or survival benefit for adjuvant radiotherapy in patients with pathological T3 disease or positive margins, adjuvant radiotherapy is recommended to $\mathrm{PCa}$ patients with high-risk of local recurrence when the PSA is undetectable $(<0.2 \mathrm{ng} / \mathrm{mL})$ [28-31]. Typically, adjuvant radiotherapy is administered 3-6 months postoperatively when incontinence has stabilized or resolved. However, administration of adjuvant radiotherapy ranged from 11 to $51 \%$ depending on the series likely varied by physician, patient, and institutional practice $[7,23,25]$. Patients with more than one adverse risk feature were reported to have more likely to receive adjuvant radiotherapy than those with an isolated adverse or high-risk feature [7]. In our study, while 12 (25\%) of the patients in the RP group received adjuvant ExRT, 9 of them also received $\mathrm{ADT}$ in combination with adjuvant ExRT. 
Table 5 Possible predictive factors in univariate and multivariate analysis

\begin{tabular}{|c|c|c|c|}
\hline & OR & $95 \% \mathrm{Cl}$ & $p$ \\
\hline \multicolumn{4}{|l|}{ All patients-univariate } \\
\hline Age & 0.96 & $0.92-1.00$ & $0.066+$ \\
\hline$P S A \geq 20 \mathrm{ng} / \mathrm{mL}$ & 1.26 & $0.66-2.41$ & 0.480 \\
\hline Clinical $\geq \mathrm{T} 3$ stage & 0.70 & $0.35-1.41$ & 0.319 \\
\hline$G S \geq 8$ at biopsy & 1.29 & $0.69-2.42$ & 0.430 \\
\hline Treatment group RP & 4.61 & $2.36-9.00$ & $<0.001^{*}$ \\
\hline \multicolumn{4}{|l|}{ All patients-multivariate } \\
\hline$P S A \geq 20 \mathrm{ng} / \mathrm{mL}$ & 1.85 & $0.95-3.59$ & $0.069+$ \\
\hline Treatment group RP & 5.35 & $2.69-10.61$ & $<0.001^{*}$ \\
\hline \multicolumn{4}{|l|}{ ExRT group-univariate } \\
\hline ADT use $<2$-year & 1.98 & $0.72-5.49$ & 0.188 \\
\hline No PLI & 2.53 & $0.93-6.91$ & $0.071+$ \\
\hline \multicolumn{4}{|l|}{ ExRT group-multivariate } \\
\hline ADT use $<2$-year & 2.42 & $0.85-6.89$ & 0.098 \\
\hline No PLI & 2.87 & $1.01-8.16$ & $0.048^{*}$ \\
\hline \multicolumn{4}{|l|}{ RP group-univariate } \\
\hline Positive surgical margin & 2.41 & $1.00-5.78$ & $0.050^{*}$ \\
\hline Pathological N1 stage & 1.97 & $0.87-4.46$ & 0.105 \\
\hline Pathological $\geq T 3$ stage & 2.17 & $0.65-7.32$ & 0.210 \\
\hline $\mathrm{GS} \geq 8$ at RP specimen & 1.83 & $0.80-4.18$ & 0.154 \\
\hline \multicolumn{4}{|l|}{ RP group-multivariate } \\
\hline Positive surgical margin\# & 2.41 & $1.00-5.78$ & $0.050^{*}$ \\
\hline \multicolumn{4}{|c|}{$\begin{array}{l}O R \text {, Odds ratio; } C l \text {, confidence Interval; } P S A \text {, prostate specific antigen; } G S, \\
\text { Gleason score; } R P \text {, radical prostatectomy; ExRT, external-beam radiotherapy; } \\
A D T \text {, androgen deprivation treatment; } P L I \text {, pelvic lymphatic irradiation } \\
\text { *indicates statistically significant data; + indicates borderline significant data } \\
\text { \#, for the } R P \text { group, positive surgical margin was the only significant risk factor } \\
\text { predicting } B F \text { in multivariate analysis }\end{array}$} \\
\hline
\end{tabular}

Furthermore, management of local and/or BF after RP with salvage radiotherapy and ADT may permit excellent long-term outcomes comparable to definitive ExRT. In our study, while $20(41.7 \%)$ of the patients in the RP group received salvage ExRT for local and/or BF, 12 of them received $\mathrm{ADT}$ in combination with salvage ExRT. In addition, the effectiveness of radiotherapy for PSA failure is greatest when given at lower levels of PSA [20]. In our study, salvage ExRT was administered at a PSA level of $\leq 1.5 \mathrm{ng} / \mathrm{mL}$ in $65 \%$ of the patients.

RP may reveal ascertainment errors particularly in patients who are characterized as high-risk by biopsy alone and may represent the sole, initial definitive therapy in some high-risk $\mathrm{PCa}$ patients with specimen-confined disease. A recent study of $1424 \mathrm{PCa}$ who underwent open or robotic-assisted RP found that $61.5 \%$ (91/148) of patients with clinical GS 8 disease on prostate biopsy were downgraded on RP [32]. In our study 7 (14.6\%) patients were downgraded on RP specimen from a high risk GS 8 to an intermediate risk GS 7. However, 5 of them had T3 disease with or without positive lymph node(s) on RP and the rest 2 patients had no other pathological or clinical high-risk factor except the initial GS 8 at biopsy.

Since high-risk PCa patients have high frequency of nodal spread, RP with PLND provides accurate staging to estimate prognosis and to inform the need for subsequent therapy [33]. In two systematic reviews, extended PLND had been suggested to increase the detection of positive nodes, with an associated improvement in survival [34, 35]. The observed survival benefit was attributed to the elimination of micro metastatic disease. In our study, all patients underwent RP with extended PLND and the median number of removed lymph nodes was 12 (5-38).

Radiotherapy dose escalation may provide better biochemical control in patients with high-risk disease [36-38]. Additionally, a better local control and improvement in distant metastases and disease-specific survival with higher doses of radiation are reported previously [36, 39]. However, an improvement in OS has not been demonstrated up to date. Thus, it brings to mind the question of whether the addition of long-term ADT to radiotherapy may be more important than dose escalation; most likely related to the effect of ADT on micro metastatic disease [40]. In our study, median definitive ExRT dose was $74 \mathrm{~Gy}$ (70-76) and $90.3 \%$ of the definitive ExRT group used ADT more than one year.

The limitations of this study are being a retrospective study, having a relatively short observation period and the use of BF as a primary endpoint since the definitions of BF are different after radiotherapy and after surgery. Furthermore, we recognize that our study is also limited by the imbalanced distributions of PSA levels and age, and the differed follow-up period between the treatment groups which could have impacted our long-term comparisons. Higher pretreatment PSA levels and older age in the definitive ExRT group than the RP group could be explained by the referral of these patients considerably to radiotherapy rather than surgery and shorter follow-up period in the RP group than the definitive ExRT group could be explained by the recently recognition of RP as an optional treatment in the context of multimodal treatment $[3,4]$ in high-risk PCa patients.

The strength of this study is using 3D-CRT or IMRT in all patients receiving ExRT and administration of long term ADT in most of the patients receiving definitive ExRT, and having extended PLND in all patents who underwent RP.

In high-risk $\mathrm{PCa}$ patients, $\mathrm{RP}$ as a component of multimodal therapy including radiotherapy and ADT may provide excellent oncological outcomes comparable to definitive radiotherapy. In our study, $66.7 \%$ of the 
patients in the RP group received either adjuvant or salvage ExRT with or without ADT and both treatment groups had similar mortality rates though the $\mathrm{BF}$ rate was higher in the RP group.

\section{Conclusion}

This study showed that while the rate of BF was significantly higher and the mean BFFS was significantly lesser in high-risk PCa patients undergoing RP than definitive ExRT; 5-year DMFS, CSS and OS were similar in both treatment groups. However, further randomized trials investigating optimal management of high-risk $\mathrm{PCa}$ and the sub-groups are needed.

\section{Abbreviations}

3D-CRT: Three dimensional conformal radiation therapy; ADT: Androgendeprivation therapy; AUA: American urological association; BF: Biochemical failure; BFFS: Biochemical failure free survival; CSS: Cancer-specific survival; CT: Computed tomography; DMFS: Distant metastasis free survival; EAU: European association of urology; ExRT: External-beam radiotherapy; GS: Gleason score; IMRT: Intensity modulated radiation therapy; OS: Overall survival; PCa: Prostate cancer; PET: Positron emission tomography; PLI: Pelvic lymphatic irradiation; PLND: Pelvic lymph node dissection; PSA: Prostatespecific antigen; RP: Radical prostatectomy

\section{Acknowledgements}

Not applicable.

\section{Funding}

None.

\section{Availability of data and materials}

The datasets used and/or analyzed during the current study are available from the corresponding author on reasonable request.

\section{Authors' contributions \\ FA made substantial contributions to conception and design of the study; acquisition, analysis and interpretation of data; and drafted and revised the manuscript. $\mathrm{VI}$ and YB contributed to conception and design of the study; acquisition, analysis and interpretation of data; and assisted with drafting and revising the manuscript. SG, HSA, HC, MZT contributed to conception and design of the study and acquisition of data; and revised the manuscript critically for important intellectual content. YS contributed to conception and design of the study; analysis and interpretation of data; and revised the manuscript critically for important intellectual content. Furthermore, all authors approved the final version of the manuscript to be published; agreed to be accountable for all aspects of the work in ensuring that questions related to the accuracy or integrity of any part of the work are appropriately investigated and resolved.}

\section{Ethics approval and consent to participate}

This study has ethics approval by the Institutional Ethics Review Board of the Cukurova University Faculty of Medicine. Additional informed consent to participate was not required due to the retrospective nature of this study.

\section{Consent for publication}

Not applicable.

\section{Competing interests}

The authors declare that they have no competing interests.

\section{Publisher's Note}

Springer Nature remains neutral with regard to jurisdictional claims in published maps and institutional affiliations.

\section{Author details}

Faculty of Medicine, Department of Radiation Oncology, Cukurova University, Adana, Turkey. ${ }^{2}$ Faculty of Medicine, Department of Urology, Cukurova University, Adana, Turkey. ${ }^{3}$ Department of Medical Oncology, Mehmet Akif Inan Training and Research Hospital, Sanliurfa, Turkey. ${ }^{4}$ Faculty of Medicine, Department of Radiation Oncology, Gaziantep University, Gaziantep, Turkey. ${ }^{5}$ Faculty of Medicine, Department of Biostatistics, Cukurova University, Adana, Turkey. ${ }^{6}$ Balcali Hastanesi, Radyasyon Onkolojisi AD, Cukurova Universitesi, 01330 Sarıcam, Adana, Turkey.

Received: 12 June 2018 Accepted: 19 December 2018 Published online: 05 January 2019

\section{References}

1. Cooperberg MR, Cowan J, Broering JM, Carroll PR. High-risk prostate cancer in the United States, 1990-2007. World J Urol. 2008:26:211-8.

2. Abdollah F, Sun $M$, Thuret $R$, Jeldres C, Tian Z, Briganti A, et al. A competing-risks analysis of survival after alternative treatment modalities for prostate cancer patients:1988-2006. Eur Urol. 2011;59:88-95.

3. Sanda MG, Cadeddu JA, Kirkby E, Chen RC, Crispino T, Fontanarosa J, et al, Clinically Localized Prostate Cancer: AUA/ASTRO/SUO Guideline. Part I: Risk Stratification, Shared Decision Making, and Care Options. J Urol. 2017; doi: https://doi.org/10.1016/j.juro.2017.11.095.

4. Mottet N, Bellmunt J, Bolla M, Briers E, Cumberbatch MG, De Santis M, et al. EAU-ESTRO-SIOG guidelines on prostate cancer. Part 1: screening, diagnosis, and local treatment with curative intent. Eur Urol. 2017;71:618-29.

5. Briganti A, Joniau S, Gontero P, Abdollah F, Passoni NM, Tombal B, et al. Identifying the best candidate for radical prostatectomy among patients with high-risk prostate cancer. Eur Urol. 2012;61:584-92.

6. Yossepowitch O, Eggener SE, Serio AM, Carver BS, Bianco FJ Jr, Scardino PT, et al. Secondary therapy, metastatic progression, and cancer-specific mortality in men with clinically high-risk prostate cancer treated with radical prostatectomy. Eur Urol. 2008:53:950-9.

7. Spahn M, Joniau S, Gontero P, Fieuws S, Marchioro G, Tombal B, et al. Outcome predictors of radical prostatectomy in patients with prostatespecific antigen greater than $20 \mathrm{ng} / \mathrm{ml}$ : a European multi-institutional study of 712 patients. Eur Urol. 2010;58:1-7.

8. Bolla M, Collette L, Blank L, Warde P, Dubois JB, Mirimanoff RO, et al. Longterm results with immediate androgen suppression an externa irradiation in patients with locally advanced prostate cancer (an EORTC study): a phase III randomised trial. Lancet. 2002;360:103-6.

9. Bolla M, Van Tienhoven G, Warde P, Dubois JB, Mirimanoff RO, Storme G, et al. External irradiation with or without longterm androgen suppression for prostate cancer with high metastatic risk: 10-year results of an EORTC randomised study. Lancet Oncol. 2010;11:1066-73.

10. Horwitz EM, Bae K, Hanks GE, Porter A, Grignon DJ, Brereton HD, et al. Tenyear follow-up of radiation therapy oncology group protocol 92-02: a phase III trial of the duration of elective androgen deprivation in locally advanced prostate cancer. J Clin Oncol. 2008;26:2497-504.

11. Johnstone PA, Ward KC, Goodman M, Assikis V, Petros JA. Radical prostatectomy for clinical T4 prostate cancer. Cancer. 2006;106:2603-9.

12. Spahn M, Weiss C, Bader P, Ströbel P, Gerharz EW, Kneitz B, et al. Longterm outcome of patients with highrisk prostate cancer following radical prostatectomy and stage-dependent adjuvant androgen deprivation. Urol Int. 2010;84:164-73.

13. Steuber T, Budäus L, Walz J, Zorn KC, Schlomm T, Chun F, et al. Radical prostatectomy improves progression-free and cancer-specific survival in men with lymph node positive prostate cancer in the prostate-specific antigen era: a confirmatory study. BJU Int. 2011;107:1755-61.

14. Siddiqui SA, Boorjian SA, Blute ML, Rangel $\amalg$, Bergstralh EJ, Karnes RJ, et al. Impact of adjuvant androgen deprivation therapy after radical prostatectomy on the survival of patients with pathological T3b prostate cancer. BJU Int. 2011;107:383-8.

15. Litwin MS, Gore JL, Kwan L, Brandeis JM, Lee SP, Withers HR, et al. Quality of life after surgery, external beam irradiation, or brachytherapy for early-s tage prostate cancer. Cancer. 2007;109:2239-47.

16. Potosky AL, Davis WW, Hoffman RM, Stanford JL, Stephenson RA, Penson DF, et al. Five-year outcomes after prostatectomy or radiotherapy for prostate cancer: the prostate cancer outcomes study. J Natl Cancer Inst. 2004;96:1358-67. 
17. Keating NL, O'Malley AJ, Smith MR. Diabetes and cardiovascular disease during androgen deprivation therapy for prostate cancer. J Clin Oncol. 2006; 24:4448-56.

18. Haque R, UlcickasYood M, Xu X, Cassidy-Bushrow AE, Tsai HT, Keating NL, et al. Cardiovascular disease risk and androgen deprivation therapy in patients with localised prostate cancer: a prospective cohort study. $\mathrm{Br}$ J Cancer. 2017;117:1233-40.

19. Genitourinary sites: Prostate cancer. In: Edge SB, Byrd DR, Compton CC, Fritz AG, Greene FL and Trotti III A, editors. American Joint Committee on Cancer Staging Manuel Seventh Edition. New York, Dordrecht, Heidelberg, London, Springer; 2015. p. 457-68.

20. Thompson IM, Valicenti RK, Albertsen P, Davis BJ, Goldenberg SL, Hahn $C$, et al. Adjuvant and salvage radiotherapy after prostatectomy: AUA/ ASTRO guideline. J Urol. 2013;190:441-9.

21. Roach M 3rd, Hanks G, Thames H Jr, Schellhammer P, Shipley WU, Sokol GH, et al. Defining biochemical failure following radiotherapy with or without hormonal therapy in men with clinically localized prostate cancer: recommendations of the RTOG-ASTRO Phoenix consensus conference. Int J Radiat Oncol Biol Phys. 2006;65:965-74.

22. Zwergel U, Suttmann H, Schroeder T, Siemer S, Wullich B, Kamradt J, et al. Outcome of prostate cancer patients with initial PSA> or $=20 \mathrm{ng} / \mathrm{ml}$ undergoing radical prostatectomy. Eur Urol. 2007;52:1058-65.

23. Ward JF, Slezak JM, Blute ML, Bergstralh EJ, Zincke H. Radical prostatectomy for clinically advanced (cT3) prostate cancer since the advent of prostate-specific antigen testing: 15-year outcome. BJU Int 2005;95:751-6.

24. Nagao K, Matsuyama H, Matsumoto H, Nasu T, Yamamoto M, Kamiryo Y, et al. Identification of curable high-risk prostate cancer using radical prostatectomy alone: who are the good candidates for undergoing radical prostatectomy among patients with high-risk prostate cancer? Int J Clin Oncol. https://doi.org/10.1007/s10147-018-1272-9.

25. Boorjian SA, Karnes RJ, Viterbo R, Rangel LJ, Bergstralh EJ, Horwitz EM, et al. Long-term survival after radical prostatectomy versus external-beam radiotherapy for patients with high-risk prostate cancer. Cancer. 2011;117: 2883-91.

26. Arcangeli G, Strigari L, Arcangeli S, Petrongari MG, Saracino B, Gomellini S, et al. Retrospective comparison of external beam radiotherapy and radical prostatectomy in high-risk, clinically localized prostate cancer. Int J Radiat Oncol Biol Phys. 2009;75:975-82.

27. Zelefsky MJ, Eastham JA, Cronin AM, Fuks Z, Zhang Z, Yamada Y, et al. Metastasis after radical prostatectomy or external beam radiotherapy for patients with clinically localized prostate cancer: a comparison of clinical cohorts adjusted for case mix. J Clin Oncol. 2010;28:1508-13.

28. Bolla M, van Poppel H, Collette L, van Cangh P, Vekemans K, Da Pozzo L, et al. Postoperative radiotherapy after radical prostatectomy: a randomised controlled trial (EORTC trial 22911). Lancet. 2005;366:572-8.

29. Bolla M, van Poppel H, Tombal B, Vekemans K, Da Pozzo L, de Reijke TM, et al. Postoperative radiotherapy after radical prostatectomy for high-risk prostate cancer: long-term results of a randomised controlled trial (EORTC trial 22911). Lancet. 2012;380:2018-27.

30. Thompson IM, Tangen CM, Paradelo J, Lucia MS, Miller G, Troyer D, et al. Adjuvant radiotherapy for pathological T3N0MO prostate cancer significantly reduces risk of metastases and improves survival: long-term followup of a randomized clinical trial. J Urol. 2009;181:956-62.

31. Wiegel T, Bottke D, Steiner U, Siegmann A, Golz R, Störkel S, et al. Phase III postoperative adjuvant radiotherapy after radical prostatectomy compared with radical prostatectomy alone in PT3 prostate cancer with postoperative undetectable prostate-specific antigen: ARO 96-02/AUO AP 09/95. J Clin Oncol. 2009;27:2924-30.

32. Qi R, Foo WC, Ferrandino MN, Davis LG, Sekar S, Longo TA, et al. Over half of contemporary clinical Gleason 8 on prostate biopsy are downgraded at radical prostatectomy. Can J Urol. 2017;24:8982-9.

33. Heidenreich A, Ohlmann CH, Polyakov S. Anatomical extent of pelvic lymphadenectomy in patients undergoing radical prostatectomy. Eur Urol. 2007:52:29-37.

34. Briganti A, Blute ML, Eastham JH, Graefen M, Heidenreich A, Karnes JR, et al. Pelvic lymph node dissection in prostate cancer. Eur Urol. 2009;55:1251-65.

35. Wagner M, Sokoloff M, Daneshmand S. The role of pelvic lymphadenectomy for prostate cancer--therapeutic? J Urol. 2008;179:408-13.

36. Kuban DA, Levy LB, Cheung MR, Lee AK, Choi S, Frank S, et al. Long-term failure patterns and survival in a randomized dose-escalation trial for prostate cancer. Who dies of disease? Int J Radiat Oncol Biol Phys. 2011;79: 1310-7.

37. Zietman AL, Bae K, Slater JD, Shipley WU, Efstathiou JA, Coen JJ, et al. Randomized trial comparing conventional-dose with high-dose conformal radiation therapy in early-stage adenocarcinoma of the prostate: long-term results from proton radiation oncology group/american college of radiology 95-09. J Clin Oncol. 2010;28:1106-11.

38. Beckendorf V, Guerif S, Le Prisé E, Cosset JM, Bougnoux A, Chauvet B, et al. 70 Gy versus 80 Gy in localized prostate cancer: 5-year results of GETUG 06 randomized trial. Int J Radiat Oncol Biol Phys. 2011;80:1056-63.

39. Zelefsky MJ, Reuter VE, Fuks Z, Scardino P, Shippy A. Influence of local tumor control on distant metastases and cancer related mortality after external beam radiotherapy for prostate cancer. J Urol. 2008;179:1368-73.

40. Roach M 3rd. Dose escalated external beam radiotherapy versus neoadjuvant androgen deprivation therapy and conventional dose external beam radiotherapy for clinically localized prostate cancer: do we need both? Strahlenther Onkol. 2007:183:26-8.
Ready to submit your research? Choose BMC and benefit from:

- fast, convenient online submission

- thorough peer review by experienced researchers in your field

- rapid publication on acceptance

- support for research data, including large and complex data types

- gold Open Access which fosters wider collaboration and increased citations

- maximum visibility for your research: over $100 \mathrm{M}$ website views per year

At BMC, research is always in progress.

Learn more biomedcentral.com/submissions 